\title{
Análise da evolução dos gastos por aluno em alguns estados brasileiros, suas respectivas capitais e sua relação com 0 Fundeb
}

\author{
Analysis of the evolution of expenditure per student in some Brazilian states \\ and their capitals and their relationship with Fundeb \\ Análisis de la evolución de los gastos por alumno en algunos estados \\ brasileños y respectivas capitales y su relación con el Fundeb
}

\section{JOSÉ MARCELINO DE REZENDE PINTO JOSETE MARIA CANGUSSÚ RIBEIRO}

\begin{abstract}
Resumo: A evolução dos recursos do Fundef/Fundeb e dos gastos com Manutenção e Desenvolvimento do Ensino por aluno foi analisada em dez estados brasileiros (MG, MS, MG, PA, PI, PR, RN, RS, SC e SP) e em suas respectivas capitaisno período de 2006 a 2014. Houve um crescimento no valor/ aluno, sendo parte desse aumento decorrente da redução dematrículas. Houve também uma diferença significativa entre os gastos por aluno das capitais com os respectivos gastos das redes estaduais, o que mostra a dificuldade de se garantir o princípio constitucional de igualdade de condições de acesso e permanência.
\end{abstract}

Palavras-chave: Gasto por aluno; Fundeb; Financiamento da educação,

\begin{abstract}
The evolution of the available resources of Fundef/Fundeb and expenses with Maintenance and Development of Education per student was analyzed in ten Brazilian states (MG, MS, MG, PA, PI, PR, RN, RS, SC, and SP) and in their respective capitals in the period 1996 to 2014. There was a growth in the expenditure per student, being part of this increase due to the reduction of enrollments. There was also a significant difference between the expenditure per student of the capitals and the respective expenses of the state, what shows the long way to guarantee the constitutional principle of equal conditions of access and permanence.
\end{abstract}

Keywords: Expenditure per student; Fundeb; Education finance.

Resumen: La evolución de los recursos disponibles del Fundef/ Fundeb y de los gastos de Mantenimiento y Desarrollo de la Enseñanza por alumno fue analisada en diez estados brasileños (MG, MS, MG, PA, PI, PR, RN, RS, SC y SP) y sus respectivas capitales en el período de 2006 a 2014. Hubo un crecimiento en 
el valor por alumno, siendo parte de ese aumento derivado de la reducción de las matrículas. Hubo también una diferencia significativa entre los gastos por alumno de las capitales con los respectivos gastos de las redes estatales, lo que muestra la dificultad de garantizar el principio constitucional de igualdad de condiciones de acceso y permanencia.

Palabras clave: Gasto por alumno; Fundeb; Financiación de la educación.

\section{INTRODUÇÃO}

Como mostram os estudos sobre custo-aluno (PARO, 1981; XAVIER; MARQUES, 1987), a remuneração do pessoal docente e dos demais servidores corresponde ao insumo de maior impacto no custo total. Portanto, para se analisar a evolução de uma política de remuneração docente é fundamental analisar o comportamento dos gastos educacionais e, em particular, analisar a evolução dos recursos disponíveis por aluno. Neste trabalho, será analisada a evolução dos recursos disponíveis por aluno no período de 2006 a 2014, tanto no que se refere aos fundos [Fundo de Manutenção e Desenvolvimento do Ensino Fundamental e de Valorização do Magistério (Fundef) e Fundo de Manutenção e Desenvolvimento da Educação Básica e de Valorização dos Profissionais da Educação (Fundeb)], quanto aos valores gastos com Manutenção e Desenvolvimento do Ensino (MDE) para os estados de Minas Gerais (MG), Mato Grosso do Sul (MS), Mato Grosso (MT), Pará (PA), Piauí (PI), Paraná (PR), Rio Grande do Norte (RN), Rio Grande do Sul (RS), Santa Catarina (SC) e São Paulo (SP), assim como para suas respectivas capitais(Belo Horizonte, Campo Grande, Cuiabá, Belém, Teresina, Curitiba, Natal, Porto Alegre, Florianópolis, São Paulo), sempre à luz da variação da matrícula na educação básica nas respectivas redes de ensino.

Particularmente, as políticas de fundos são importantes na discussão acerca da remuneração, uma vez que tanto o Fundef, regulamentado pelaLei no 9.424/96(BRASI, 1996), quanto o Fundeb, pela Lei no 11.494/2007 (BRASIL, 2007), preveem a aplicação mínima de $60 \%$ de seus recursos para o pagamento do pessoal do magistério. Levantamento do MEC feito em 2016 a partir de declarações dadas pelos próprios municípios indica que dos 5.570 municípios, 2.533 não pagavam o Piso Salarial Profissional Nacional (PSPN), regulamentado pela Lei $\mathrm{n}^{\circ}$ 11.738/ 2008 e que a visa servir como um patamar mínimo de remuneração.A principal justificativa para o não cumprimento do PSNP por parte dos prefeitos refere-se à insuficiência dos recursos do Fundeb para essa finalidade. Segundo a Confederação Nacional dos Municípios (CNM) somente o pagamento do salário dos professores consome, em média, 78,4\% dos recursos do fundo (G1, 2017). 
Para realização do presente estudo foram utilizados os dados de matriculas, extraídos dos microdados do Censo Escolar para o período de 2007 a 2013, e da Consulta à matrícula, paraos anos de2006 e 2014, coletados e disponibilizados pelo Instituto Nacional de Estudos e Pesquisas Educacionais Anísio Teixeira (INEP).

Quanto aos dados referentes às despesas com manutenção e desenvolvimento do ensino, foram utilizados os Relatórios Resumidosde Execuções Orçamentárias, publicados pelo Sistema de Informações sobre Orçamentos Públicos em Educação (Siope), considerando-se apenas aqueles recursos destinados à Educação Básica. Para os dados do Fundef/Fundeb, tomou-se como referência os relatórios consolidados do FNDE. Para o cálculo do valor por aluno, usou-se sempre a matrícula do ano em que os recursos são executados. Cabe ressaltar que todos os dados financeiros foram corrigidos com base no Índice Nacional de Preços ao Consumidor (INPC) para se garantir a análise da evolução real dos gastos. A Tabela 1 a seguir, aponta a evolução do valor/aluno disponível nas redes estaduais dos estados indicados.

\section{Tabela 1 - Evolução do valor disponível por aluno do Fundef/Fundeb na rede estadual de ensino para estados selecionados- 2006 a 2014 (R\$ de 2014)}

\begin{tabular}{|c|c|c|c|c|c|c|c|c|c|c|}
\hline UF & $\mathbf{2 0 0 6}$ & $\mathbf{2 0 0 7}$ & $\mathbf{2 0 0 8}$ & $\mathbf{2 0 0 9}$ & $\mathbf{2 0 1 0 ^ { * }}$ & $\mathbf{2 0 1 1}$ & $\mathbf{2 0 1 2}$ & $\mathbf{2 0 1 3}$ & $\mathbf{2 0 1 4}$ & $\begin{array}{c}\text { Variação } \\
\mathbf{2 0 1 4 / 2 0 1 0}\end{array}$ \\
\hline $\mathrm{MG}$ & 1.770 & 2.029 & 2.321 & 2.133 & $\mathbf{2 . 3 9 7}$ & $\mathbf{2 . 5 2 8}$ & $\mathbf{2 . 6 7 0}$ & $\mathbf{2 . 8 3 9}$ & $\mathbf{2 . 8 9 3}$ & 1,2 \\
\hline $\mathrm{MS}$ & 2.313 & 2.528 & 2.743 & 2.533 & 2.650 & 2.964 & 3.073 & 3.295 & 3.351 & 1,3 \\
\hline $\mathrm{MT}$ & 1.934 & 2.039 & 2.442 & 2.306 & 2.254 & 2.408 & 2.497 & 2.738 & 3.017 & 1,3 \\
\hline $\mathrm{PA}$ & 1.160 & 1.535 & 1.748 & 1.817 & 1.843 & 2.580 & 2.725 & 2.687 & 2.778 & 1,5 \\
\hline $\mathrm{PI}$ & 1.253 & 1.548 & 1.742 & 1.820 & 1.880 & 2.434 & 2.517 & 2.884 & 2.796 & 1,5 \\
\hline $\mathrm{PR}$ & 2.053 & 2.178 & 2.276 & 2.233 & 2.311 & 2.620 & 2.771 & 3.057 & 3.210 & 1,4 \\
\hline $\mathrm{RN}$ & 1.929 & 1.885 & 2.072 & 1.960 & 2.211 & 2.494 & 2.713 & 2.743 & 3.108 & 1,4 \\
\hline $\mathrm{RS}$ & 2.412 & 2.329 & 2.554 & 2.714 & 2.981 & 3.169 & 3.218 & 3.499 & 3.692 & 1,2 \\
\hline $\mathrm{SC}$ & 2.250 & 2.934 & 3.185 & 2.506 & 2.803 & 3.221 & 3.291 & 3.328 & 3.532 & 1,3 \\
\hline $\mathrm{SP}$ & 2.944 & 2.103 & 2.667 & 2.954 & 3.292 & 3.552 & 3.629 & 3.889 & 3.741 & 1,1 \\
\hline
\end{tabular}

* Ano em que o Fundeb atingiu a plenitude dos recursos.

Fonte: Siope e Relatório Consolidado do Fundef (para 2006). Para MG (2014) e RS (2013 e 2014), como não havia informações no Siope, a fonte consultada foi o relatório consolidado do Fundeb da STN.

Antes de analisar os resultados, é importante lembrar que, em 2006, ainda estava em vigência o Fundef, que visava à destinação do recurso para o atendimento do Ensino Fundamental regular e, portanto, entre os alunos 
considerados estavam incluídos apenas os referentes a essa etapa de ensino. Já o Fundeb entrou em vigor de maneira progressiva, chegando a 100\% da matrícula da Educação Básica apenas em 2009. A mesma progressividade se deu com ampliação dos recursos aportados ao Fundo pelos estados e municípios, assim como com a complementação da União.

Tendo em vista essa fase de transição no montante de matrículas incorporadas ao novo fundo, assim como no montante dos recursos, é que se considerou, na última coluna da Tabela 1, a evolução no período 2010 a 2014, quando o fundo já se encontrava em sua dinâmica plena. Para esse período, observa-se uma evolução no valor por aluno mais intensa apenas nos estados que receberam complementação da União. Assim, Pará e Piauí apresentaram um crescimento real de 50\%, o maior índice nos estados avaliados. Rio Grande do Norte, que recebeu um pequeno complemento nos anos de 2011 a 2014 cresceu $40 \%$, assim como o Paraná, que não recebe complemento. Na sequência vêm os estados de Mato Grosso do Sul, Mato Grosso e Santa Catarina, com 30\%, seguidos por Minas Gerais e Rio Grande do Sul, com 20\% e São Paulo, com apenas 10\%. Quando comparamos o valor de 2014 com o valor de 2006, último ano do Fundef observa-se que, mais uma vez, os estados que apresentam crescimento significativo (mais de 100\%) são Piauí e Pará, exatamente em função da mudança na fórmula de cálculo da complementação da União, que aumentou significativamente o valor disponível por aluno nos entes federados que recebem essa complementação (PINTO, 2015).

Para se compreender um pouco mais a dinâmica dessa evolução, é importante analisar como a matrícula da Educação Básica na rede estadual variou no período, lembrando que a EC 59/2009(BRASIL, 2009) determinou a obrigatoriedade do ensino de 4 a 17 anos de idade até o ano de 2016, o que gerou uma expectativa de queda no valor disponível por aluno em função da incorporação às redes públicas de ensino de 3,9 milhões de crianças e jovens que se encontravam fora da escola (PINTO; ALVES, 2011), em especial na préescola, com impacto nas redes municipais e, no ensino médio, com impacto nas redes estaduais. Os dados são apresentados na Tabela 2. 
Tabela 2 - Evolução da matrícula na educação básica da rede estadual para estados selecionados - 2006 a 2014 (x 1.000)

\begin{tabular}{|c|c|c|c|c|c|c|c|c|c|c|}
\hline UF & 2006 & 2007 & 2008 & 2009 & 2010 & 2011 & 2012 & 2013 & 2014 & $\begin{array}{l}\text { Variação } \\
\text { 2014/2006 }\end{array}$ \\
\hline MG & 2.643 & 2.551 & 2.525 & 2.447 & 2.390 & 2.352 & 2.268 & 2.219 & 2.171 & 0,82 \\
\hline MS & 323 & 305 & 295 & 291 & 282 & 279 & 268 & 258 & 252 & 0,78 \\
\hline MT & 477 & 439 & 436 & 428 & 432 & 444 & 445 & 436 & 414 & 0,87 \\
\hline PA & 793 & 790 & 720 & 724 & 711 & 681 & 664 & 644 & 632 & 0,80 \\
\hline $\mathrm{PI}$ & 371 & 336 & 342 & 331 & 313 & 294 & 278 & 238 & 232 & 0,62 \\
\hline PR & 1.371 & 1.354 & 1.339 & 1.314 & 1.311 & 1.267 & 1.225 & 1.168 & 1.132 & 0,83 \\
\hline $\mathrm{RN}$ & 392 & 359 & 345 & 325 & 310 & 303 & 286 & 280 & 261 & 0,67 \\
\hline RS & 1.375 & 1.322 & 1.260 & 1.200 & 1.158 & 1.118 & 1.084 & 1.051 & 1.013 & 0,74 \\
\hline SC & 849 & 739 & 714 & 680 & 666 & 631 & 589 & 564 & 553 & 0,65 \\
\hline SP & 5.331 & 5.078 & 5.006 & 4.862 & 4.713 & 4.604 & 4.479 & 4.351 & 4.217 & 0,79 \\
\hline
\end{tabular}

Fonte: Microdados do Censo Escolar (2007-2013)/ INEP e Consulta à matrícula (2006 e 2014)/ INEP

Os dados apresentados na Tabela 2 apontam uma grande queda na matrícula das redes estaduais no período. A maior queda ocorre exatamente no Piauí, estado que apresentou a maior variação no valor aluno, seguido por Santa Catarina e Rio Grande do Norte. Os demais estados, apresentaram uma queda que ficou em torno de $20 \%$, o que pode indicar que o aumento no valor disponível por aluno decorre de uma estratégia de redução da matrícula nos sistemas estaduais; isso em um momento em que se esperava uma ampliação do atendimento em virtude da Emenda Constitucional no 59 (EC 59 /2009)e do próprio Plano Nacional de Educação 2014-2024 (PNE 2014-2024), aprovado pela Lei no 13.005 , de 25 de junho de 2014, que já se encontrava em discussão no período. Parte dessa queda pode decorrer da transferência de matrículas no Ensino Fundamental para os municípios e de políticas de correção de fluxo, mas esses fatores não parecem suficientes para explicar a redução, ainda mais em virtude da demanda de expansão no Ensino Médio. De qualquer maneira, é importante analisar como a matrícula na Educação Básica evoluiu no mesmo período nas redes municipais. Os dados são apresentados na Tabela 3. 


\section{Tabela 3 - Evolução das matrículas na Educação Básica da rede municipal para estados selecionados -2006 a 2014 (x 1.000)}

\begin{tabular}{|c|c|c|c|c|c|c|c|c|c|c|}
\hline UF & $\mathbf{2 0 0 6}$ & $\mathbf{2 0 0 7}$ & $\mathbf{2 0 0 8}$ & $\mathbf{2 0 0 9}$ & $\mathbf{2 0 1 0}$ & $\mathbf{2 0 1 1}$ & $\mathbf{2 0 1 2}$ & $\mathbf{2 0 1 3}$ & $\mathbf{2 0 1 4}$ & $\begin{array}{c}\text { Variação } \\
\mathbf{2 0 1 4 / 2 0 0 6}\end{array}$ \\
\hline MG & 1.941 & 1.928 & 1.913 & 1.900 & 1.868 & 1.826 & 1.807 & 1.789 & 1.787 & 0,92 \\
\hline MS & 300 & 306 & 313 & 315 & 314 & 316 & 318 & 324 & 330 & 1,10 \\
\hline MT & 371 & 354 & 352 & 352 & 339 & 339 & 336 & 339 & 341 & 0,92 \\
\hline PA & 1.613 & 1.557 & 1.565 & 1.581 & 1.555 & 1.550 & 1.545 .480 & 1.551 & 1.537 & 0,95 \\
\hline PI & 652 & 618 & 607 & 604 & 573 & 561 & 554 & 570 & 561 & 0,86 \\
\hline PR & 1.059 & 1.047 & 1.047 & 1.031 & 1.011 & 980 & 997 & 1.009 & 1.011 & 0,95 \\
\hline RN & 495 & 468 & 461 & 461 & 450 & 440 & 431 & 430 & 423 & 0,86 \\
\hline RS & 948 & 937 & 947 & 954 & 951 & 948 & 944 & 932 & 930 & 0,98 \\
\hline SC & 642 & 641 & 649 & 659 & 657 & 671 & 690 & 694 & 697 & 1,09 \\
\hline SP & 3.879 & 3.869 & 3.950 & 3.920 & 3.878 & 3.807 & 3.816 & 3.811 & 3.833 & 0,99 \\
\hline
\end{tabular}

Fonte: Microdados do Censo Escolar (2007-2013)/ INEP e Consulta à matrícula (2006 e 2014)/ INEP

Os dados da Tabela 3 indicam que também as redes municipais, salvo as de Mato Grosso do Sul, que cresceu 10\%, e de Santa Catarina, com 9\%, apresentaram queda ou estabilização na matrícula. Chama atenção o caso de Piauí e Rio Grande do Norte, em que houve queda significativa nas matrículas da rede estadual e municipal, o que ajuda a entender o crescimento no valor disponível por aluno. Considerando que o estudo de Pinto e Alves (2011) leva em conta a dinâmica demográfica no período e que não houve mudanças significativas nos indicadores de fluxo escolar, os dados parecem apontar que, ao contrário dos anos iniciais do Fundef, em que houve uma corrida atrás dos alunos, isso deixou de ocorrer com o Fundeb. Ao que tudo indica, a estratégia política adotada, principalmente por parte dos governadores, mas também por prefeitos, foi a de reduzir o número de alunos atendidos para fazer os recursos dos fundos renderem mais. A se confirmar essa política, trata-se de fato preocupante, pois como já comentado, ela ocorreu em um momento em que se esperava uma ampliação do atendimento, tanto nas redes municipais, quanto estaduais.

Resta analisar, agora, como se comportaram os recursos disponíveis por aluno nas redes estaduais, quando se considera o conjunto de recursos gastos com MDE, a partir dos dados divulgados no Siope. 


\section{Tabela 4 - Gasto por aluno da Educação Básica com manutenção e desenvolvimento do ensino na rede estadual de estados selecionados - 2006 a 2014 (R\$ de 2014)}

\begin{tabular}{|c|c|c|c|c|c|c|c|c|c|c|}
\hline UF & $\mathbf{2 0 0 6}$ & $\mathbf{2 0 0 7}$ & $\mathbf{2 0 0 8}$ & $\mathbf{2 0 0 9}$ & $\mathbf{2 0 1 0}$ & $\mathbf{2 0 1 1}$ & $\mathbf{2 0 1 2}$ & $\mathbf{2 0 1 3}$ & $\mathbf{2 0 1 4}$ & $\begin{array}{c}\text { Variação } \\
\mathbf{2 0 1 4 / 2 0 0 6}\end{array}$ \\
\hline $\mathrm{MG}$ & 1.709 & 2.809 & 3.455 & 3.234 & 3.565 & $\mathbf{4} .305$ & 4.800 & $\mathbf{4 . 9 0 2}$ & $\mathrm{nd}$ & 0,0 \\
\hline $\mathrm{MS}$ & 2.222 & 3.597 & 3.747 & 4.492 & 4.922 & 5.524 & 7.425 & 5.443 & 5.927 & 2,7 \\
\hline $\mathrm{MT}$ & 1.362 & 2.581 & 2.945 & 2.829 & 2.642 & 3.185 & 3.741 & 3.444 & 3.821 & 2,8 \\
\hline $\mathrm{PA}$ & 1.383 & 1.610 & 2.053 & 2.494 & 2.498 & 3.241 & 3.232 & 3.109 & 3.204 & 2,3 \\
\hline $\mathrm{PI}$ & 987 & 2.116 & 2.294 & 2.817 & 3.086 & 3.596 & 3.749 & 3.338 & 4.601 & 4,7 \\
\hline $\mathrm{PR}$ & 2.268 & 2.447 & 2.952 & 3.051 & 3.239 & 3.589 & 4.025 & 4.655 & 5.434 & 2,4 \\
\hline $\mathrm{RN}$ & 1.516 & 2.140 & 2.882 & 2.628 & 2.409 & 3.857 & 3.723 & 3.326 & 3.725 & 2,5 \\
\hline $\mathrm{RS}$ & 1.788 & 1.991 & 2.597 & 2.930 & 3.332 & 5.053 & 5.579 & $\mathrm{nd}$ & $\mathrm{nd}$ & 0,0 \\
\hline $\mathrm{SC}$ & 1.782 & 2.250 & 2.722 & 2.577 & 2.921 & 3.314 & 3.691 & 3.815 & 4.060 & 2,3 \\
\hline SP & 2.352 & 3.184 & 3.711 & 4.030 & 4.691 & 5.322 & 5.179 & 5.718 & 6.720 & 2,9 \\
\hline
\end{tabular}

Fonte: Siope (Relatório Resumido da Execução Orçamentária) e Censo Escolar (2010-2013)/ INEP e Consulta à matrícula (2014)/INEP.

Os dados da Tabela 4 apontam para um grande crescimento nos recursos gastos por aluno em MDE no período, em especial até 2012, quando se iniciou uma pequena queda, com exceção de MG, SC e SP e PR. Essa queda já indica os problemas pelos quais passava a economia do país e que se acentuam a partir de 2014. Uma informação interessante que se pode deduzir da Tabela 4 se refere à grande diferença no gasto por aluno entre os estados pesquisados, sendo que a diferença, considerando o valor médio no período, entre SP e PA chega a 79\%.

Cabe comentar ainda que, ao que parece, o Siope ainda apresenta algumas incongruências, quando se observa, por exemplo, o valor do gasto/aluno de MS, em 2012, ou o de SP, em 2014, que parecem representar descontinuidades na série histórica. Cabe lembrar que, em última análise, é desses recursos destinados a MDE que se origina a remuneração dos professores e demais profissionais da educação, e não apenas do Fundeb. Contudo, é importante lembrar que é esperada uma correlação relativamente estável, no caso dos estados, entre os recursos recebidos do Fundo e os gastos com MDE, pois, ao contrário dos municípios, no caso dos Estados todas suas receitas integram o Fundeb (ICMS, IPVA e ITBI) e, portanto, os recursos adicionais ao Fundo que possuem decorrem apenas do diferencial de 5\% (nos casos em que a Constituição Estadual fixa a vinculação mínima em 25\%) que se aplica sobre os mesmos impostos e que não integram o Fundeb. Seria interessante, portanto, comparar os gastos por aluno em MDE (Tabela 4) com os recursos disponibilizados por aluno no Fundeb (Tabela 1). A 
Tabela 5 apresenta essa razão para os estados indicados. Foi considerado apenas o período 2010 a 2014, quando o Fundeb encontrava-se em seu funcionamento pleno.

\section{Tabela 5 - Razão entre o gasto/aluno (MDE) na rede estadual selecionada e valor/aluno do Fundeb nos estados selecionados - 2010 a 2014}

\begin{tabular}{|c|c|c|c|c|c|}
\hline UF & $\mathbf{2 0 1 0}$ & $\mathbf{2 0 1 1}$ & $\mathbf{2 0 1 2}$ & $\mathbf{2 0 1 3}$ & $\mathbf{2 0 1 4}$ \\
\hline $\mathrm{MG}$ & 1,49 & 1,70 & 1,80 & 1,73 & - \\
\hline $\mathrm{MS}$ & 1,86 & 1,86 & 2,42 & 1,65 & 1,77 \\
\hline $\mathrm{MT}$ & 1,17 & 1,32 & 1,50 & 1,26 & 1,27 \\
\hline $\mathrm{PA}$ & 1,36 & 1,26 & 1,19 & 1,16 & 1,15 \\
\hline $\mathrm{PI}$ & 1,64 & 1,48 & 1,49 & 1,16 & 1,65 \\
\hline $\mathrm{PR}$ & 1,40 & 1,37 & 1,45 & 1,52 & 1,69 \\
\hline $\mathrm{RN}$ & 1,09 & 1,55 & 1,37 & 1,21 & 1,20 \\
\hline $\mathrm{RS}$ & 1,12 & 1,59 & 1,73 & - & - \\
\hline $\mathrm{SC}$ & 1,04 & 1,03 & 1,12 & 1,15 & 1,15 \\
\hline $\mathrm{SP}$ & 1,43 & 1,50 & 1,43 & 1,47 & 1,80 \\
\hline
\end{tabular}

Fonte: elaboração dos autores a partir dos dados das Tabelas 1 e 4.

De maneira geral, os resultados obtidos parecem indicar ainda incongruências, considerando-se a grande oscilação na série histórica de um mesmo estado, como se pode observar no resultado de 2014 para SP e de 2012, para MS e para o RS nos três anos da série. De qualquer maneira, na comparação entre os estados, pode-se concluir que os recursos adicionais por aluno, na média da série histórica, superam em 50\% os recursos propiciados pelo Fundebem apenas dois estados: MG e MS. Em tese, estados mais municipalizados teriam maior folga com esses recursos adicionais, mas os resultados são contraditórios em relação a essa hipótese. De qualquer forma, é importante ressaltar que os recursos do Fundeb por aluno seconstituem em bom indicador do potencial de gastos totais de uma rede estadual de ensino e se pode afirmar que há um limite bem baixo de recursos adicionais a serem utilizados, por exemplo, na remuneração docente. Como se discutirá a seguir, a situação é bem distinta no caso dos municípios das capitais.

$\mathrm{Na}$ Tabela 6 é apresentada a evolução dos gastos por alunos na educação básica dos municípios das capitais dos estados analisados, tendo por base os dados declarados ao Siope para o período de 2006 a 2014. 


\section{Tabela 6 - Gastos por aluno (MDE) na Educação Básica na rede municipal das capitais selecionadas - 2006 a 2014 (R\$ de 2014)}

\begin{tabular}{|c|c|c|c|c|c|c|c|c|c|c|}
\hline Capital & $\mathbf{2 0 0 6}$ & $\mathbf{2 0 0 7}$ & $\mathbf{2 0 0 8}$ & $\mathbf{2 0 0 9}$ & $\mathbf{2 0 1 0}$ & $\mathbf{2 0 1 1}$ & $\mathbf{2 0 1 2}$ & $\mathbf{2 0 1 3}$ & $\mathbf{2 0 1 4}$ & $\begin{array}{c}\text { Variação } \\
\mathbf{2 0 1 4 / 2 0 0 6}\end{array}$ \\
\hline $\begin{array}{c}\text { Belo } \\
\text { Horizonte }\end{array}$ & 4.626 & 5.680 & 6.490 & 6.465 & 7.243 & 8.076 & 8.888 & 8.135 & 8.360 & 1,81 \\
\hline $\begin{array}{c}\text { Campo } \\
\text { Grande }\end{array}$ & 3.515 & 3.678 & 4.081 & 4.200 & 4.478 & 4.967 & 5.209 & 5.624 & 6.091 & 1,73 \\
\hline Cuiabá & 3.121 & 3.430 & 3.961 & 4.016 & 4.514 & 4.758 & 5.619 & 5.969 & 6.236 & 2,00 \\
\hline Belém & 2.977 & 3.204 & 3.765 & 3.558 & 3.976 & 4.754 & 5.156 & 5.647 & 5.743 & 1,93 \\
\hline Teresina & 2.397 & 2.295 & 2.513 & 2.692 & 2.932 & 3.451 & 3.608 & 3.936 & 4.362 & 1,82 \\
\hline Curitiba & 5.535 & 5.449 & 5.589 & 5.862 & 6.233 & 7.072 & 7.654 & 8.445 & 8.494 & 1,53 \\
\hline Natal & 3.521 & 3.522 & 3.803 & 4.789 & 4.865 & 5.026 & 4.798 & 5.505 & 6.652 & 1,89 \\
\hline Porto Alegre & 7.038 & 6.480 & 10.469 & 10.638 & 11.563 & 12.854 & 14.376 & 15.627 & 16.470 & 2,34 \\
\hline Florianópolis & 7.211 & 6.729 & 7.251 & 8.174 & 8.837 & 8.801 & 9.065 & 9.654 & 10.256 & 1,42 \\
\hline São Paulo & 5.932 & 5.707 & 6.387 & 7.853 & 10.018 & 11.803 & 12.463 & 13.460 & 14.018 & 2,36 \\
\hline Fon: Sire
\end{tabular}

Fonte: Siope (Relatório Resumido da Execução Orçamentária) e Censo Escolar (2010-2013)/ INEP e Consulta à matrícula (2014)/INEP.

Os dados indicam uma evolução positiva no gasto por aluno no período, sendo que na maioria das capitais, a variação foi superior 80\%. Florianópolis, com um crescimento de $42 \%$ e Curitiba, com 53\% foram os municípios que apresentaram menor evolução, enquanto Porto Alegre, com 134\% e São Paulo, com 136\% foram as capitais com maior crescimento. Essas duas cidades foram também as que apresentaram maior valor de gasto/aluno, superando em três vezes o valor de Teresina, a capital com menor valor. Cabe comentar também que, de maneira geral, a evolução no valor do gasto por aluno foi mais intensa no período de 2006 a 2010, perdendo ímpeto nos anos finais da série.

De forma análoga às redes estaduais, parte do crescimento do gasto/ aluno está também relacionado à queda nas matrículas. É o que mostra a Tabela 7. 


\section{Tabela 7 - Evolução da matrícula na Educação Básica na rede municipal nas capitais selecionadas- 2006 a 2014}

\begin{tabular}{|c|c|c|c|c|c|c|c|c|c|c|}
\hline Capital & $\mathbf{2 0 0 6}$ & $\mathbf{2 0 0 7}$ & $\mathbf{2 0 0 8}$ & $\mathbf{2 0 0 9}$ & $\mathbf{2 0 1 0}$ & $\mathbf{2 0 1 1}$ & $\mathbf{2 0 1 2}$ & $\mathbf{2 0 1 3}$ & $\mathbf{2 0 1 4}$ & $\begin{array}{c}\text { Variação } \\
\mathbf{2 0 1 4 / 2 0 0 6}\end{array}$ \\
\hline $\begin{array}{c}\text { Belo } \\
\text { Horizonte }\end{array}$ & 181.104 & 180.760 & 177.431 & 174.337 & 174.054 & 170.581 & 167.526 & 164.859 & 165.283 & 0,91 \\
\hline $\begin{array}{c}\text { Campo } \\
\text { Grande }\end{array}$ & 86.622 & 90.045 & 93.944 & 95.690 & 96.272 & 96.943 & 97.895 & 97.141 & 97.292 & 1,12 \\
\hline Cuiabá & 49.545 & 48.285 & 47.865 & 47.332 & 46.456 & 47.041 & 47.450 & 47.500 & 48.325 & 0,98 \\
\hline Belém & 72.489 & 73.776 & 73.594 & 75.033 & 71.611 & 69.340 & 71.047 & 70.669 & 70.370 & 0,97 \\
\hline Teresina & 82.522 & 89.219 & 94.991 & 93.637 & 89.713 & 90.867 & 91.422 & 90.788 & 86.176 & 1,04 \\
\hline Curitiba & 134.523 & 131.505 & 136.198 & 134.323 & 132.730 & 131.335 & 131.953 & 132.139 & 132.886 & 0,99 \\
\hline Natal & 59.944 & 59.416 & 59.449 & 57.151 & 56.162 & 55.963 & 54.626 & 52.869 & 51.511 & 0,86 \\
\hline Porto Alegre & 60.526 & 56.919 & 55.403 & 55.511 & 55.724 & 54.104 & 53.040 & 50.664 & 49.563 & 0,82 \\
\hline Florianópolis & 24.941 & 26.175 & 26.339 & 26.883 & 26.892 & 27.199 & 27.417 & 27.930 & 27.612 & 1,11 \\
\hline São Paulo & 995.714 & 935.588 & 967.554 & 908.224 & 856.210 & 776.208 & 766.292 & 753.326 & 746.335 & 0,75 \\
\hline
\end{tabular}

Fonte: Microdados do Censo Escolar (2007-2013)/ INEP e Consulta à matrícula (2006 e 2014)/ INEP

Os dados da Tabela 7 indicam uma queda na matrícula no período, seja em relação a 2006, ano inicial da série, nos casos de Belo Horizonte, Cuiabá, Belém, Curitiba, Natal, Porto Alegre e São Paulo, seja em relação a 2012, nos casos de Campo Grande e Teresina, ou 2013, no caso de Florianópolis. Não por coincidência, as capitais em que maior foi a evolução no gasto/aluno, Porto Alegre e São Paulo, também maior foi a queda nas matrículas, 18\% e 25\%, respectivamente. Campo Grande, com crescimento de 12\%, Florianópolis, com 11\% e Teresina, com 4\%, foram as únicas capitais da amostra com crescimento positivo em relação ao início da série histórica. No caso de Florianópolis esse pode ser um dos fatores explicativos para o pequeno crescimento do gasto por aluno mostrado na Tabela 6.

Para se compreender melhor a dinâmica das matrículas da rede municipal apresentada na Tabela 7, a Tabela 8 traz os dados do percentual de matrículas da rede municipal em relação ao total de matrículas nas capitais. Nota-se que Curitiba, Florianópolis e Teresina apresentaram,de 2010 a 2013, crescimento contínuo na participação,sendo mais de $30 \%$ das matrículas ofertadas pela rede municipal de ensino. Exceto em 2011, Belém e Campo Grande também seguem essa tendência.

Em 2014, todas as capitais apresentaram queda no percentualde participação em relação a 2013. Chama atenção a situação de Campo Grande, em que,mesmo com a queda na participação, a rede municipal respondia por cerca de $47 \%$ das matrículas. Essa grande participação ajuda a entender o gasto por 
aluno (MDE) relativamente baixo apresentado por Campo Grande na Tabela 6. Já Porto Alegre, a capital que apresentou o menor percentual de matrículas em redes municipais é também aquela que apresenta o maior valor de gasto por aluno (MDE). Esse fato gera um problema sério, do ponto de vista de equidade, pois, enquanto um estudante de Porto Alegre que frequentou uma escola estadual teve um gasto médio, em 2012 (último ano disponível) de R \$ 5.579, seu colega que frequentou uma escola municipal coube um gasto médio de $\mathrm{R} \$ 14.376$, no mesmo ano. Esses dados mostram os limites que persistem na política de fundos desde a implantação do Fundef, seja do ponto de vista de garantir um padrão aceitável de gastos por aluno, seja na perspectiva de assegurar a equalização das oportunidades educacionais (OLIVEIRA, 1999; PINTO, 2015)

\section{Tabela 8 - Percentual de matrícula da rede municipal em relação ao totalde matrícula nas capitais -2010 a 2014(em \%)}

\begin{tabular}{|c|c|c|c|c|c|}
\hline Capital & $\mathbf{2 0 1 0}$ & $\mathbf{2 0 1 1}$ & $\mathbf{2 0 1 2}$ & $\mathbf{2 0 1 3}$ & $\mathbf{2 0 1 4}$ \\
\hline Belo Horizonte & 30,0 & 29,8 & 29,7 & 29,7 & 29,4 \\
\hline Campo Grande & 47,3 & 46,8 & 47,3 & 47,7 & 46,9 \\
\hline Cuiabá & 32,0 & 31,6 & 31,7 & 31,6 & 31,2 \\
\hline Belém & 19,6 & 19,6 & 19,9 & 20,2 & 20,4 \\
\hline Teresina & 36,1 & 37,3 & 38,2 & 39,8 & 38,9 \\
\hline Curitiba & 30,5 & 31,1 & 31,3 & 31,9 & 31,8 \\
\hline Natal & 26,0 & 26,2 & 26,1 & 25,9 & 25,2 \\
\hline Porto Alegre & 17,5 & 17,1 & 17,0 & 16,6 & 16,3 \\
\hline Florianópolis & 29,4 & 30,3 & 30,4 & 31,0 & 29,5 \\
\hline São Paulo & 30,0 & 27,6 & 27,4 & 27,1 & 26,8 \\
\hline
\end{tabular}

Fonte:Censo Escolar (2010-2013)/ INEP e Consulta à matrícula (2014)/INEP.

Ainda em relação à Tabela 8 , observou-se que,no período analisado, a variação na participação da rede municipal na oferta foi relativamente pequena, situando-se em patamar inferior a um ponto percentual (p.p.),à exceção de São Paulo, onde houve uma queda de 3,2 p.p. no período.

Finalmente, na Tabela 9, será mostrada a razão entre os valores por aluno disponibilizados pelo Fundeb, em média, nos estados, com os gastos por aluno nas capitais. Cabe comentar que para boa parte dos municípios do interior dos estados, a maior parte dos recursos advém do Fundeb(PINTO, 2015).O que se pretende com essa comparação é aquilatar o nível de recursos adicionaisde que as capitais dispõem em decorrência de sua receita própria de impostos, os quais, 
como se sabe, não compõem a cesta de tributos do Fundeb. Como no caso das redes estaduais, a análise aqui é feita a partir de 2010, quando o Fundeb atingiu sua vigência plena, em termos de matrícula e recursos financeiros.

\section{Tabela 9 - Razão entre os Gasto/aluno (MDE) nas capitais e o valor/ aluno do Fundeb no Estado - 2010 a 2014}

\begin{tabular}{|c|c|c|c|c|c|}
\hline Capital & $\mathbf{2 0 1 0}$ & $\mathbf{2 0 1 1}$ & $\mathbf{2 0 1 2}$ & $\mathbf{2 0 1 3}$ & $\mathbf{2 0 1 4}$ \\
\hline Belo Horizonte & 3,0 & 3,2 & 3,3 & 2,9 & 2,9 \\
\hline Campo Grande & 1,7 & 1,7 & 1,7 & 1,7 & 1,8 \\
\hline Cuiabá & 2,0 & 2,0 & 2,3 & 2,2 & 2,1 \\
\hline Belém & 2,2 & 1,8 & 1,9 & 2,1 & 2,1 \\
\hline Teresina & 1,6 & 1,4 & 1,4 & 1,4 & 1,6 \\
\hline Curitiba & 2,7 & 2,7 & 2,8 & 2,8 & 2,6 \\
\hline Natal & 2,2 & 2,0 & 1,8 & 2,0 & 2,1 \\
\hline Porto Alegre & 3,9 & 4,1 & 4,5 & 4,5 & 4,5 \\
\hline Florianópolis & 3,2 & 2,7 & 2,8 & 2,9 & 2,9 \\
\hline São Paulo & 3,0 & 3,3 & 3,4 & 3,5 & 3,7 \\
\hline
\end{tabular}

Fonte: Tabela 6 e Tabela 1.

A Tabela 9 ajuda a entender porque os municípios das capitais, de forma geral, conseguem proporcionar remuneração e carreira bem superior, ao das redes estaduais do respectivo estado (CAMARGO; JACOMINI, 2015). Enquanto os últimos dependem basicamente dos recursos do Fundeb, os primeiros, de maneira geral, contam com recursos adicionais significativos advindos da vinculação constitucional sobre sua receita própria de impostos (Impostos sobre a Propriedade Predial e Territorial Urbana, Imposto Sobre Serviços e Imposto sobre Transmissão Inter Vivos).

Com exceção de Campo Grande e de Teresina, com fatores 1,8 e 1,6, respectivamente, as demais capitais conseguem, em relação aos recursos por aluno do Fundeb, duplicar (Natal, Cuiabá, Belém, Curitiba), triplicar (Florianópolis e Belo Horizonte) e até quadruplicar os gastos, caso de Porto Alegre e, em menor medida, São Paulo. Isso mostra a importância da receita própria dos municípios, que incluem o IPTU, ISS e ITBI, em propiciar recursos adicionais além daqueles garantidos pelo Fundeb no âmbito de cada unidade federada.

A análise da Tabela 9 em comparação com a Tabela 8 traz alguns elementos que podem ajudar a entender as diferenças entre as capitais. Assim, a razão foi maior em Porto Alegre e São Paulo, que possuem as redes menos municipalizadas. Na situação oposta encontram-se Teresina e Campo Grande, 
que são as capitais da amostra que apresentam maior índice de municipalização da Educação Básica. Já Belém, com baixo índice de municipalização, parece não seguir esse padrão, o que mostra a influência de outros fatores, particularmente do esforço fiscal de cada município e da capacidade contributiva da população, a qual, no caso das capitais da região Norte e Nordeste, tende a ser mais baixa.

O efeito desses dois fatores (grau de municipalização e capacidade de gerar receita própria) ajuda a entender, em particular, a situação de Teresina, que apresenta a menor razão da amostra. Já Florianópolis, capital com forte indústria turística, pode ser um bom exemplo do efeito da capacidade contributiva de alguns municípios litorâneos que abrigam um grande número de imóveis para temporada, como acontece também com Santos e Guarujá em São Paulo.

\section{CONSIDERAÇÕES FINAIS}

A análise dos recursos disponíveis no âmbito do Fundeb e dos gastos por aluno com manutenção e desenvolvimento do ensino na Educação Básica aponta para algumas constatações preliminares:

- Houve um crescimento no valor/aluno tanto no âmbito do Fundeb, quanto nos gastos com MDE;

- Parte desse aumento decorre da redução das matrículas, tanto nas redes estaduais quanto nas redes dos municípios das capitais;

- Essa queda de matrículas na Educação Básica preocupa, pois tendo em vista a EC 59/2009 a expectativa seria de seu crescimento;

- Os recursos adicionais ao Fundeb têm impacto mediano nas redes estaduais, mas muito significativo no caso das capitais dos estados analisados;

- As diferenças nos gastos por aluno das redes estaduais nos estados analisados ainda persistem e são significativas, mesmo com a vigência do Fundeb e, no caso das capitais dos mesmos estados, as discrepâncias tendem a ser ainda mais significativas;

- Há uma diferença significativa a maior (2 a 3 vezes), entre os gastos por aluno dos municípios das capitais quando comparados com os respectivos gastos das redes estaduais, o que mostra ainda o longo caminho para se garantir o princípio constitucional de igualdade de condições de acesso e permanência, mesmo se considerada apenas a rede pública de cada unidade federada. Se a comparação for feita com a rede privada a situação é muito mais crítica (PINTO, 2014).

Finalmente, cabe um comentário sobre a dimensão dos recursos propiciados pelo Fundeb no Brasil, considerando que, em especial na maioria dos municípios e, mesmo em boa parte dos estados das regiões norte e nordeste, 
basicamente são esses os recursos que asseguram o funcionamento cotidiano das escolas de Educação Básica, pagando os salários dos profissionais da educação e garantindo os poucos recursos para as demais despesas de custeio e para os tão necessários e quase inexistentes gastos de investimento.

Pois bem, considerando 2014, o último ano da série histórica analisada, 20 milhões de alunos, ou seja, metade dos alunos registrados no censo no mesmo ano tiveram disponibilizados recursos abaixo de $R$ \$250/mês ( $R$ \$3.000/ano), e para 33 milhões de estudantes, ou seja, 81\% do total, o valor foi abaixo de R $\$ 300$ / mês ( $\mathrm{R} \$ 3.600 /$ ano). Quando esses valores são comparados com as mensalidades das escolas privadas frequentadas pelas crianças de classe média, que custam, no mínimo, a depender do local, de duas a três vezes esses valores, ficam evidentes os limites desse fundo em assegurar uma educação pública de qualidade. A título de exemplo, um valor de gasto de $\mathrm{R} \$ 3.000$ por aluno-ano, permitiria pagar uma remuneração bruta mensal média de $\mathrm{R} \$ 1.890,00$ para os professores da Educação Básica, considerando uma jornada de meio período para os alunos e uma jornada docente integral; valor que, com certeza, exerce pouco poder de atração para os potenciais professores, realidade constatada por diferentes estudos (SAMPAIO ET AL. 2002; ALVES; PINTO, 2011).

Finalmente, em um momento em que se discute no Congresso Nacional, a transformação do Fundeb em fundo permanente e a implementação do Custo Aluno Qualidade inicial (CAQi), é fundamental atentar para as peculiaridades no padrão de gasto por aluno das capitais, bem como reafirmar a importância da garantia de recursos financeiros suficientes para o estabelecimento e a implementação de um valor por aluno suficiente para a garantia de qualidade social e equidade em todo o território nacional.

\section{REFERÊNCIAS}

ALVES, T.; PINTO, J. M. R. Remuneração e características do trabalho docente no Brasil: um aporte dos dados do Censo Escolar e da PNAD. Cadernos de Pesquisa, v.41, p.1 - 10, 2011.

BRASIL. Lei n. 13.005, de 25 de junho de 2014. Aprova o Plano Nacional de Educação - PNE e dá outras providências. Diário Oficial da União, Brasilia, DF, 26/06/2014. 
BRASIL. Emenda Constitucional $\mathrm{n}^{\circ}$ 59, de 11 de novembro de 2009. Acrescenta $\int 3^{\circ}$ ao art. 76 do Ato das Disposições Constitucionais Transitórias para reduzir, anualmente, a partir do exercício de 2009, o percentual da Desvinculação das Receitas da União incidente sobre os recursos destinados à manutenção e desenvolvimento do ensino de que trata o art. 212 da Constituição Federal, dá nova redação aos incisos I e VII do art. 208, de forma a prever a obrigatoriedade do ensino de quatro a dezessete anos e ampliar a abrangência dos programas suplementares para todas as etapas da educação básica, e dá nova redação ao $\$ $4^{\circ}$ do art. 211 e ao $\int 3^{\circ}$ do art. 212 e ao caput do art. 214, com a inserção neste dispositivo de inciso VI. Diário Oficial da União, Brasilia, DF, 12/11/2009.

BRASIL. Lei n ${ }^{\circ}$ 11.738, de 16 de julho de 2008. Regulamenta a alínea "e" do inciso III do caput do art. 60 do Ato das Disposições Constitucionais Transitórias, para instituir o piso salarial profissional nacional para os profissionais do magistério público da educação básica. Diário Oficial da União, Brasília, DF, 17/07/2008.

BRASIL. Lei n. 11.494, 2007. Regulamenta o Fundo de Manutenção e Desenvolvimento da Educação Básica e de Valorização dos Profissionais da Educação - FUNDEB, de que trata o art. 60 do Ato das Disposições Constitucionais Transitórias; altera a Lei no 10.195, de 14 de fevereiro de 2001; revoga dispositivos das Leis nos 9.424, de 24 de dezembro de 1996, 10.880, de 9 de junho de 2004, e 10.845, de 5 de março de 2004; e dá outras providências. Diário Oficial da União, Brasília, DF, 22/06/2007.

BRASIL. Lei n. 9.424, 1996. Dispõe sobre o Fundo de Manutenção e Desenvolvimento do Ensino Fundamental e de Valorização do Magistério, na forma prevista no art. 60, $\ 7^{\circ}$, do Ato das Disposições Constitucionais Transitórias, e dá outras providências. Diário Oficial da União, Brasília, DF, 26/12/1996.

CAMARGO, R.B.; JACOMINI, M.A. (orgs.) Vencimento e remuneração docente no Brasil: resultados de pesquisa. São Paulo: Xamã, 2015.

G1. Maioria dos municípios não paga o piso salarial aos professores, diz MEC: levantamento foi feito pelo MEC com base nas informações declaradas pelos próprios municípios. 2017.Disponível em: <https://g1.globo.com/educacao/ noticia/maioria-dos-municipios-nao-paga-o-piso-salarial-aos-professores-dizmec.ghtml>.Acesso em: 1 fev. 2018. 
INSTITUTO NACIONAL DE ESTUDOS E PESQUISAS EDUCACIONAIS ANÍSIO TEIXEIRA (Inep). Microdados do Censo Escolar. 2007 a 2013. Disponível em: < http://portal.inep.gov.br/web/guest/microdados>. Acesso em: 1 jun. 2017.

INEP. Portal do INEP. Censo Escolar. Consulta matrícula. 2006 e 2014. Disponível em: http://matricula.educacenso.inep.gov.br/. Acessado em: 1 jun. 2017.

OLIVEIRA, C. A municipalização do ensino brasileiro. In: OLIVEIRA, C. et al. Municipalização do ensino no Brasil. Belo Horizonte: Atlântica, 1999.

PARO, V.H. Estudo comparativo de custo-aluno nos diversos graus e modalidades de ensino. São Paulo: Fundação Carlos Chagas; Secretaria de Estado de Educação de São Paulo, 1981.

PINTO, J. M. R.O Fundeb na perspectiva do custo aluno qualidade. Revista Em Aberto, v.28, p.101-117, 2015.

PINTO, J.M.R. Dinheiro traz felicidade? A relação entre insumos e qualidade na educação. Archivos Analíticos de Políticas Educativas / Education Policy Analysis Archives. , v.22, p.19-25, 2014.

PINTO, J.M.R e ALVES, T. O Impacto Financeiro da Ampliação da Obrigatoriedade Escolar no Contexto do FUNDEB. Educação \& Realidade, vol. 36, núm. 2, p. 605-624, maio-agosto, 2011.

SAMPAIO, C.E.M. et al. Estatísticas dos professores no Brasil. Revista Brasileira de Estudos Pedagógicos, Brasília, v. 83, n. 203/204/205, p. 85-120, jan./dez. 2002.

XAVIER, A.C.R.; MARQUES, A.E.S. Custo Direto de Funcionamento das escolas de $\mathbf{1}^{\mathbf{0}}$ grau (por regiões geográficas). Brasília, MEC/SEB, 1987.

ALINE KAZUKO SONOBE é Mestre em Educação pela Universidade de São Paulo, doutoranda do Programa de Pós-Graduação em Educação da Universidade Federal do Paraná e integrante do Laboratório de Dados Educacionais. E-mail: kazuko.as@gmail.com 
JOSÉ MARCELINO DE REZENDE PINTO é professor da Faculdade de Filosofia, Ciências e Letras de Ribeirão Preto da Universidade de São Paulo e editor da Revista Fineduca. E-mail: jmrpinto@fffclrp.usp.br

JOSETE MARIA CANGUSSÚ RIBEIRO é Doutora e Mestre em Educação, graduada em Pedagogia, docente da área de políticas educacionais dos cursos de graduação em Letras e Biologia da Universidade do Estado de Mato Grosso Campus de Tangará da Serra-MT. E-mail: josetemcr@gmail.com

Recebido em maio de 2018 Aprovado em julho de 2018 